\title{
Occurrence and Antimicrobial-Resistant Salmonella Serovars Isolated from Turkey Carcasses and Broiler Turkey Farms in Meknès-Morocco
}

\author{
Abdellah El Allaoui and Fouzia Rhazi Filali \\ Equipe Microbiologie et Santé, Département de Biologie, Laboratoire de Chimie Biologie Appliquées à l'Environnement, Université Moulay Ismail Faculté des Sciences, \\ Zitoune Meknès, Morocco \\ ${ }^{*}$ Corresponding author: El Allaoui A, Equipe Microbiologie et Santé, Département de Biologie, Laboratoire de Chimie Biologie Appliquées à l'Environnement, \\ Université Moulay Ismail Faculté des Sciences, Zitoune Meknès, Morocco, Tel: +212 5355-37321; E-mail: alaouixsaraa@hotmail.com
}

Received date: October 27, 2015, Accepted date: October 19, 2016, Published date: October 25, 2016

Copyright: @ 2016 EL Allaoui A, et al. This is an open-access article distributed under the terms of the Creative Commons Attribution License, which permits unrestricted use, distribution, and reproduction in any medium, provided the original author and source are credited.

Keywords: Salmonella; antibacterial resistance; $16 \mathrm{~S}$ rDNA; phylogeny; virulence genes; bacteriological quality

\section{Commentary}

Between November 2011 to November 2013 a total of 680 samples were collected: pools of droppings $(n=600)$ and drinking water $(n=80)$. The rate of insulation of Salmonella is important (35\%), and the isolated serotypes are worrying: $36 \mathrm{~S}$. Kentucky, $15 \mathrm{~S}$. Saintpaul, $8 \mathrm{~S}$. Parkroyal and 3 S. Ruzizi.

They have relatively high rates of resistance to tetracycline (79 \%) and streptomycin $(72.5 \%)$, followed by resistance to nalidixic acid (37.1\%), ciprofloxacin (33.9 \%). Three strains of S. Agona Expanded Spectrum Betalactamase (ESBL) which have a high level of resistance to ceftriaxone with a minimum inhibitory concentration (CMI) of 16 $\mu \mathrm{g} / \mathrm{Ml}$ were detected.

According to the norms of the water intended for the watering of poultry, for the lock of the line of watering, $100 \%$ of samples are of unacceptable quality as regards the fecal coliforms, Escerichia coli, fecal streptococci and sulfitoréducteurs and entérocoques. While more than $90 \%$ of drinking water samples are of a satisfactory quality according to $\mathrm{pH}$, a nitrite, conductivity, nitrate and Iron.

Simultaneously, the nine discovered risk factors were significantly associated with Salmonella contamination. These risk factors highlight the risks of the broiler channel, particularly linked to poor technical and hygiene practices.

On the other hand, a total of 228 samples of turkey meat and giblets were collected randomly from retail outlets in Meknès. Ninety six samples were analysed for the presence of the following bacteria: Escherichia coli (E. coli), coagulase positive Staphylococcus (SA), Clostridium perfringens (CP), for total aerobic mesophilic flora (FMAT) and thermo tolerant coliforms (TC). Their rate of compliance with hygiene standards for FMAT, TC, E. coli, SA and CP are respectively $64.6,18.8,11.4,53.1$ and $64.6 \%$.

The level of contamination from supermarkets was identified as significantly lower $(\mathrm{p}<0.05)$ the other sites. According to the microbiological criteria, $80 \%$ of samples did not meet the standards for E. coli and total coliforms. $64.6 \%(n=64)$ and $53.1 \%(n=51)$ samples are of acceptable quality for CP and SA among which $8,3 \%$ of samples could be linked to a foodborne due to a concentration of coagulase positive Staphylococcus coagulase-positive upper in $5 \log 10 \mathrm{ufc} / \mathrm{g}$.

After the study of the biochemical and the culture characteristics of the isolated Salmonella strains (47/192), followed by serotyping and antibiotic susceptibility testing, the PCR was used to confirm the identification of the Salmonella species and the search for genes encoding the virulence factors. The genotypic comparison within the same serotype is based on the analysis of plasmid content and the pulsed field electrophoresis (PFGE).

Out of 192 samples examined, $24.5 \%$ were contaminated with Salmonella. The sizes of the plasmids obtained ranged from 1.8 to 128 $\mathrm{kb}$. The highest percentage of resistance was found to the following antimicrobial agents: Bacitracin (97.8\%), amoxicillin (61.7\%), streptomycin (44.6\%), triméthoprime (34\%), nalidixic acid colistin (19.1\%) and ciprofloxacin (17\%), the drug commonly prescribed to treat salmonellosis. On the other hand, $97.8 \%$ of isolates were found to be resistant to one or more of the antibiotics tested and $100 \%$ of S. Kentucky $(\mathrm{n}=8)$ are resistant to ciprofloxacin and nalidixic acid.

The tests of sensitivity to antibiotics showed for the first time in Morocco the presence of the serotype highly resistant. It comes to $S$. Agona bla SHV resistant to the C3G carried by a plasmid conjugation: the resistance profile (amoxicillin, chloramphenicol, streptomycin, bacitracin, cefotaxime, ceftazidime, céftriaxone, colistine) is an ESBL with a minimum inhibitory concentration for ceftriaxone $16 \mu \mathrm{g} / \mathrm{ml}$.

After transfer by way of conjugation, the plasmid carrying the resistance encoding ESBLs, we identified the bla SHV gene by PCR, then, it is sequenced and identified by bioinformatics methods: it is bla SHV12 that underwent four mutations compared to wild SHV gene.

All Salmonella strains tested were positive for the virulence genes (spiA, sifA, spaN, sopB, sipB, iroN, orgA, sitC and $\operatorname{prgH}$ ), whereas they are positive for virulence genes $\mathrm{spvC}$ and $\mathrm{spvB}$ at respective frequencies of $6.3 \%$ and $0 \%$. The results of the molecular epidemiology of the Salmonella obtained by analysis of plasmid content and by pulsed field gel electrophoresis (PFGE) showed a genetic diversity within the studied serotype.

In this study, the overall performance of $16 \mathrm{~S}$ rDNA sequence analysis was excellent: $100 \%$ strains possessed a $16 \mathrm{~S}$ rDNA sequence with $\geq 97 \%$ similarity to that of a genus Salmonella, in that it separates more or less the different serotypes in clusters or sub clusters and. However, in order to improve this performance, efforts should be made to complete $16 \mathrm{~S}$ rDNA databases with high-quality sequences and develop electronic tools for sequence comparison and interpretation.

The results of this work show the emergence of Salmonella non Typhi resistant to the beta-lactam antibiotics and quinolones isolated from turkey meat. The rationalization of the use of the fluoroquinolones in practice veterinary and medical constitutes an urgency of public health in order to cease selecting resistant mutants and to limit human contamination risk. On the other hand, the presence of virulence genes represents a serious threat to public health. 
Citation: Allaoui A, Filali FR (2016) Occurrence and Antimicrobial-Resistant Salmonella Serovars Isolated from Turkey Carcasses and Broiler Turkey Farms in Meknès-Morocco. Ferment Technol 5: 132. doi:10.4172/2167-7972.1000132

Page 2 of 2

More studies to track the evolution of virulence factors among

Salmonella must be encouraged. 